УДК 902.3

https://doi.org/10.24852/2587-6112.2021.6.308.314

\title{
КОРРОЗИЯ ПРЕДМЕТОВ ИЗ ЖЕЛЕЗА И ЖЕЛЕЗНЫХ СПЛАВОВ В МОРСКОЙ ВОДЕ
}

\author{
(C) 2021 г. Е. И. Носова
}

Статья представляет собой обзор новейших европейских исследований по проблемам коррозии железа в морской воде. Подобные повреждения характерны для объектов морской археологии, в частности кораблекрушений. Долгое время исследование подобных коррозионных процессов было осложнено тем, что пробы, отобранные в морской воде, быстро окислялись на воздухе, и их состав существенно менялся. В начале 1980х гг. после разработки методики пробоотбора исследование подводных артефактов стало развиваться быстрее и эффективнее. Прежде всего, в статье рассмотрены базовые процессы коррозии железа и факторы, стимулирующие их. К таковым относятся: соленость окружающей морской воды, концентрация растворенного кислорода, микробиологическая активность, $\mathrm{pH}$, температура и характер циркуляции воды, которые, в свою очередь, влияют на преобладание других параметров. Затем, детально описаны продукты коррозии железа, характерные для морской среды. Наконец, освещена роль микроорганизмов в коррозионном процессе и их влияние на сохранность памятника.

Ключевые слова: Подводная археология, кораблекрушения, коррозия, железо, железные сплавы.

\section{CORROSION OF IRON AND IRON ALLOYS IN SEAWATER}

\section{E. I. Nosova}

The article is a review of the latest European research on the problems of iron corrosion in seawater. Such damages are typical for objects of marine archaeology, in particular shipwrecks. For a long time, the study of such corrosion processes was complicated by the fact that samples taken in seawater quickly oxidized in the air and their composition changed significantly. In the early 1980s, after the development of sampling techniques, the study of underwater artifacts corrosion began to develop faster and more efficiently. First of all, the basic processes of iron corrosion and the factors that stimulate them are discussed in the article. These include seawater salinity, oxygen concentration, microbiological activity, $\mathrm{pH}$, temperature, and water circulation patterns, which, in turn, influence the prevalence of other parameters. Next, the iron corrosion products characteristic of the marine environment are described in detail. Finally, the role of microorganisms in the corrosion process and their influence on the preservation of the monument are highlighted.

Keywords: Underwater archaeology, shipwrecks, corrosion, iron, iron alloys.

Научная реставрация базируется на знании материала, его структурных особенностей и характера взаимодействия с различными средами, в которых найден и хранится объект. Изучение процессов деградации материала способствуют выработке методов реставрации и условий дальнейшего хранения в музейных собраниях. Знание структуры материала также способствует лучшей атрибуции его в изделиях и более тщательному описанию физического состояния.

Особым объектом для изучения являются артефакты, извлеченные из морской среды. Чаще всего такие условия формируются в результате морских кораблекрушений. Специфика условий и сложность работы с такими артефактами приводит к тому, что на сегодняшний день исследований объектов из морской воды не много. Компенсировать нехватку материала в этой области можно отчасти за счет комплексного анализа литературы из разных областей (морской биологии, геохимии и др.). В настоящей статье мы хотели бы предложить вниманию читателя обзор англоязычной литературы последних лет.

Наиболее распространенными материалами, извлекаемыми из морской воды, являются металлы и древесина (для кораблестроения до нач. XX в.). В настоящей работе мы сосредоточимся на проблемах коррозии железа, как одного из самых распространенных материалов, особенно с учетом интереса к исследованию кораблекрушений периода Второй Мировой войны, возросшего в последние годы. 
Взаимосвязь между местом кораблекрушения железного или стального судна и обнаруженными там продуктами коррозии часто может быть сложной, но выделяют основные факторы, влияющие на скорость и механизмы коррозии. К этим факторам относятся: соленость окружающей морской воды, концентрация растворенного кислорода, микробиологическая активность, $\mathrm{pH}$, температура и характер циркуляции воды, которые, в свою очередь, влияют на преобладание других параметров. Эти факторы обусловили структуру данной работы. Прежде всего, будут рассмотрены базовые процессы железа и основные агенты деструкции. Затем, мы сосредоточимся на наиболее распространенных продуктах деградации, характерных для морского железа и процессе их образования. Наконец, будет рассмотрена роль микроорганизмов в процессе коррозии. В заключении будет подведен итог краткому обзору тематики и приведены рекомендации по хранению предметов из железа, извлечённых из морской среды.

Деградация железа в морской воде: характеристика основных процессов

Рассмотрим базовые механизмы коррозии железа и его сплавов в воде. Когда металлическое соединение подвергается воздействию газообразной формы кислорода $\left(\mathrm{O}_{2}\right)$ под водой, возникает коррозия. В случае металлов или сплавов на основе железа продуктом этой реакции является метагидроксид железа $(\mathrm{FeO}(\mathrm{OH}))$, образующий ржаво-красные отложения, типичные для коррозии железа. Эта реакция состоит из отдельных электрохимических реакций, которые происходят в разных местах на поверхности металла. В некоторых местах на металле образуются ионы $\left(\mathrm{Fe}^{2+}\right)$ в результате реакции окисления, также известной как анодная реакция. В других местах вдоль поверхности металла кислород принимает электроны из металла и восстанавливается; этот процесс называется катодной реакцией. Для поддержания нейтральности заряда по всей поверхности металла необходимо, чтобы катионы (заряженные ионы) диффундировали в катодные области, а анионы (отрицательно заряженные ионы) - в анодные области. Такая диффузия ионов легко происходит в растворах с высокой ионной проводимостью, например, в морской воде. Для того, чтобы коррозия продолжалась быстры- ми темпами, необходимо также определенное движение реагентов и продуктов. Кислород должен подаваться преимущественно в катодные области, а ионы железа должны удаляться из анодных областей. Ионы железа могут удаляться либо путем диффузии в окружающую морскую воду, например, путем дальнейшего окисления в ионы железа $\mathrm{Fe}^{3+}$, либо путем образования нерастворимых осадков и сложных ионов, что происходит при соединении железа с другими видами ионов. (North, 1982; Selwyn, Sirois, Argyropoulos, 1999).

Особенно сильно влияет на коррозию железа соленость в связи с активностью ионов хлоридов $\left(\mathrm{Cl}^{-}\right)$. Они обладают высокой подвижностью и притягиваются к ионам металла, образующимся в анодных областях. Таким образом, хлорид-ионы увеличивают общую способность металла к коррозии и приводят к образованию уникальных продуктов деградации, таких как метагидроксид железа. В морской воде и других растворах, содержащих хлорид-ионы, происходит деградация железа, похожая на автокаталитический процесс, возникающий во время питтинговой или щелевой коррозии. Во время автокаталитического процесса, протоны $\left(\mathrm{H}^{+}\right)$, которые образуются при расщеплении молекул воды, известной также как реакции гидролиза, и мигрирующие хлорид-ионы образуют соляную кислоту $(\mathrm{HCl})$ и ускоряют коррозию железа путем устойчивых циклических реакций. Преобладающим соединением, которое первоначально образуется при коррозии железа в присутствии хлорид-ионов, является хлорид железа (II) $\left(\mathrm{FeCl}_{2}\right)$. Хлорид железа (II) может перейти в хлорид железа (III) $\left(\mathrm{FeCl}_{3}\right)$, но так как $\mathrm{FeCl}_{2}$ является растворимой солью железа, то, скорее всего, в присутствии кислорода, растворенного в воде, будет происходить образование метагидроксидов железа $\mathrm{FeO}(\mathrm{OH})$ (Hamilton, 1999) (Selwyn, Sirois, Argyropoulos, 1999) (Selwyn, Mckinnon, Argyropoulos, 2001). Также может образовываться промежуточная форма $\mathrm{FeOCl}$ (North, Pearson, 1978).

Роль кислорода в подводной коррозии металлических объектов сложна. Для артефактов на основе железа он преимущественно служит катодным деполяризатором. Иными словами, первичная катодная реакция, протекающая в железных или стальных объектах, 
подвергающихся воздействию морской воды, заключается в восстановлении кислорода, в результате чего образуются гидроксильные $\left(\mathrm{OH}^{-}\right)$ионы. Колебания концентрации кислорода вдоль определенных точек на поверхности артефактов из железа или стали также могут вызывать коррозионные процессы, так как области с наименьшей концентрацией кислорода становятся анодными из-за избирательной аэрации и страдают от ускоренной коррозии (Moore, 2015). Эффективное поступление кислорода в воду способствует ускорению процесса коррозии (Rahmanto, Gunawan, Nuryanto, 2013).

Присутствие сероводорода, генерируемого некоторыми бактериями, в качестве окислителя приводит к образованию пирита $\left(\mathrm{FeS}_{2}\right)$. Образование пирита возможно также другим путем. Ионы железа, которые выделяются из анодных областей артефактов в процессе коррозии в анодной воде, могут вступать в реакцию с ионами серы, которые образуются в процессе биологического сульфатного восстановления. Это приводит к образованию частично стабильных сульфидов железа, например, макинавита $\left(\mathrm{Fe}_{9} \mathrm{~S}_{8}\right)$ или грейгита $\left(\mathrm{Fe}_{3} \mathrm{~S}_{4}\right)$. Эти метастабильные сульфиды железа могут затем вступать в реакцию с элементарной серой или полисульфидами с образованием в конечном итоге пирита $\left(\mathrm{FeS}_{2}\right)$. (Duan et al., 2008; Kasten, Jørgensen, 2000).

В целом, процессы коррозии металла в соленой воде достаточно сложны и зависят от набора конкретных факторов, присущих чаще всего определенному месту. Активным участником коррозионных процессов в морской воде являются бактерии и микроорганизмы, способные самостоятельно выступать в качестве активаторов коррозии из-за синтезируемых ими продуктов жизнедеятельности. Ниже мы рассмотрим процесс образования основных продуктов коррозии железа в морской воде, а затем - роль бактерий в коррозии.

Продукть коррозии железа в морской cpede

Существенной проблемой изучения продуктов коррозии железа, извлеченных из морской среды, было то, что они очень быстро окислялись на воздухе, и доставить их в лабораторию для исследований в неизменном виде было невозможно. Попытки использовать морскую воду или слабый раствор $\mathrm{NaOH}$ для ее имитации по-прежнему приводили к значительным изменениям в составе продуктов коррозии. В начале $1980 x$ годов была предпринята попытка решить эту проблему и получить более точный, неизменный состав. Образцы извлекались в контейнерах с морской водой, затем в лабораторных условиях вода откачивалась с помощью вакуума в течение четырех дней. Затем в камеру подавался сухой азот, и дальнейшие исследования проводились в азотной среде (North, 1982).

Для сохранности железа большое значение имеет состав сплава и метод обработки. При относительно высоком содержании углерода в металле часто сохраняются общие формы артефакта, так как ионы железа диффундировали наружу, образовав минералы, повторяющие очертания объекта. При деградации кованого железа происходит анодное растворение, которое оставляет после себя волокнистые, древоподобные структуры, возникшие в результате шлаковых включений металла, так как продукты коррозии постепенно вымывались абразивным воздействием течений, биоповреждениями, что открывало металл морским водам.(North, Pearson, 1978).

Наиболее распространенными продуктами коррозии на железных артефактах являются $\alpha$-, $\beta$ - и $\gamma$-модификации $\mathrm{FeO}(\mathrm{OH}), \mathrm{Fe}_{2} \mathrm{O}_{3}$ и аморфный $\mathrm{FeO}(\mathrm{OH})$. Следует отметить, что хотя хлорид-ион и считается наиболее активным разрушителем железа, хлорид железа (II) $\left(\mathrm{FeCl}_{2}\right)$ и хлорид железа (III) $\left(\mathrm{FeCl}_{3}\right)$ были идентифицированы на ряде морских артефактов железа, но только в небольших концентрациях, под толстым слоем других продуктов коррозии. Это объясняется тем, что хлорид железа неустойчив к гидролизу. Присутствие $\mathrm{FeOCl}$ возможно, не доказано убедительно.

Лепидокрокит или $\gamma$-модификации $\mathrm{FeO}(\mathrm{OH})$ редко встречается при коррозии железа в морской воде, он значительно больше распространен при коррозии железа в земле. Две другие модификации весьма распространены. Гетит или $\alpha-\mathrm{FeO}(\mathrm{OH})$ является наиболее устойчивым продуктом коррозии, встречающимся на морском железе, и практически все продукты коррозии, образующиеся в природных условиях, стремятся перейти в него. Гетит осаждается при медленном гидролизе водных соединений железа при рН более 3,5. Он также образуется при 
длительном старении аморфного $\mathrm{FeO}(\mathrm{OH})$. Интересно отметить, что $\alpha-\mathrm{FeO}(\mathrm{OH})$, обнаруженный на морском железе, имеет сильно искаженную кристаллическую структуру с многочисленными дефектами решетки. $\beta$ - и $\gamma$-модификации $\mathrm{FeO}(\mathrm{OH})$ имеют значительно меньше дефектов, но менее всего искажениям кристаллической решетки подвержен магнетит.

В редких случаях на железе образуется так называемая «зеленая ржавчина». Экспериментально показано, что это смешанное валентное соединение, выпадающее из раствора при окислении растворенного иона железа при нейтральном или слабо щелочном рН в присутствии хлорид-ионов. Оно имеет зеленый цвет и типичный состав $\mathrm{Fe}(\mathrm{OH})_{2} \cdot 1 / 4 \mathrm{FeO}(\mathrm{OH})$. Зеленая ржавчина была идентифицирована на отливках из железа, а также на полосках из низкоуглеродистой стали, погруженных в искусственный раствор морской воды. Зеленая ржавчина также образуется в качестве промежуточного продукта коррозии на анодированной стали, поляризованной с помощью внешнего тока. Обнаружено, что коррозия проходит через несколько этапов, что приводит к образованию $\gamma-\mathrm{FeO}(\mathrm{OH})$ и медленному превращению в магнетит. Обнаружено, что зеленая ржавчина обладает переменным содержанием хлорид-ионов, которое может быть уменьшено в ходе консервационных мероприятий (Fors, Sandström, 2006).

В анаэробных условиях, например, в отложениях загрязненных гаваней и устьев рек, важным продуктом коррозии железа является сульфид железа. В качестве отдельных минеральных видов известно не менее шести сульфидов железа: пирит (кубический $\mathrm{FeS}_{2}$ ), марказит (орторомбический $\mathrm{FeS}_{2}$ ), пирротин (гексагональный или моноклинический $\mathrm{Fe}_{1-\mathrm{x}} \mathrm{S}, 0<\mathrm{x}<0,2$ ), сметит (ромбоэдрический $(\mathrm{Fe}, \mathrm{Ni})_{3+\mathrm{x}} \mathrm{S}_{4}, 0<\mathrm{x}<0,3$ ), грейгит (кубический $\mathrm{Fe}_{3} \mathrm{~S}_{4}$ ) и макинавит (тетрагональный $\mathrm{Fe}_{1+\mathrm{x}} \mathrm{S}$, $0<\mathrm{x}<0,1)$. Природа образующегося в процессе коррозии сульфида железа зависит от $\mathrm{pH}$, температуры, а также от наличия кислорода и различных анионов. Первоначально образуется макинавит, но в присутствии соляного раствора и растворенного углекислого газа макинавит неустойчив и может переходить в другие сульфиды железа (Gilberg, Seeley, 1981).
На образцах железа поднятых со шведского корабля «Васа», затонувшего в 1628 г. при спуске на воду, большинство солей были идентифицированы методом рентгеновской порошковой дифракции как сульфаты. Были обнаружены гидратированные сульфаты железа, розенит $\left(\mathrm{FeSO}_{4} \bullet \mathrm{H}_{2} \mathrm{O}\right)$, мелантерит $\left(\mathrm{FeSO}_{4} \cdot 7 \mathrm{H}_{2} \mathrm{O}\right)$ и натроярозит $\left(\mathrm{NaFe}_{3}(-\right.$ $\left.\left.\mathrm{SO}_{4}\right)_{2}(\mathrm{OH})_{6}\right)$, а также гипс, $\mathrm{CaSO}_{4} \cdot 2 \mathrm{H}_{2} \mathrm{O}$ и элементарная сера (орторомбическая $\mathrm{S}_{8}$ ) в виде крошечных кристаллов на поверхностях корпусных брусьев (Fors, Sandström, 2006).

Продукты коррозии морского железа обычно содержат большое количество аморфных материалов. Их аморфная природа затрудняет их изучение, так как наиболее зарекомендовавший себя метод рентгеновской дифракции в данном случае оказывается бессилен. Формированию аморфных соединений может способствовать ряд различных факторов. Материал можно описать как рентгеновски аморфный, если он находится в стекловидном состоянии, если он состоит из чрезвычайно мелких кристаллов или если он имеет сильно нарушенную решетчатую структуру. В большинстве случаев оксигидроксид железа является аморфным. Скорость образования кристаллических частиц прямо пропорциональна концентрации растворенных ионов $\mathrm{Fe}^{2+}$ и $\mathrm{Fe}^{3+}$. Аморфный материал может быть получен путем быстрого воздушного окисления и гидролиза растворов ионов $\mathrm{Fe}^{2+}$ или быстрого гидролиза растворов ионов $\mathrm{Fe}^{3+}$ при кислом $\mathrm{pH}$. Рентгеновски аморфный материал на морском железе, вероятно, состоит из микрокристаллического $\alpha-\mathrm{FeO}(\mathrm{OH})$ и оксигидроксида железа, имеющего сильно неупорядоченную решетчатую структуру. Последний, вероятно, образуется в результате быстрого воздушного окисления и разложения основных хлоридов железа или карбонатов, как только погруженный объект извлекается из моря и подвергается воздействию атмосферы. Этот аморфный материал содержит большое количество хлорид-ионов. Наличие таких ионов играет важную роль в термодинамической устойчивости осадков метагидроксида железа, и их включение согласуется с формированием сильно неупорядоченной решетчатой структуры (Gilberg, Seeley, 1981).

Роль микроорганизмов в коррозионных nроиессах 
Не меньшее влияние на состояние артефактов в морской воде оказывают микроорганизмы(Little, Gerke, Lee, 2014; p. 946). Причем следует отметить, что именно последствия их жизнедеятельности являются наиболее характерной особенностью артефактов, извлеченных из морской воды, по сравнению с объектами, извлеченными из земли. Затонувшие корабли действуют как искусственные рифы и обеспечивают твердую поверхность для многих различных форм жизни, что делает их сосредоточением биогеохимического круговорота. В зависимости от типа микроорганизмы могут способствовать либо сохранению, либо ухудшению состояния затонувшего судна. Даже в пределах одного затонувшего судна процессы деградации могут различаться в зависимости от условий.

Наиболее часто на артефактах из морской среды обнаруживают Deltaproteobacteria, способные к сульфатной редукции и вносящие вклад в биокоррозию. Характерно, что по мере увеличению глубины залегания их количество увеличивается. Прочие распространенные таксоны, такие как Gammaproteobacteria, Phycisphaerae u Dehalococcoidaceae, также были очень многочисленны во всех исследованных объектах. Железобактерии (FeOB) и сульфатредуцирующие бактерии (SRB) вносят свой вклад в биокоррозию и разрушение железных и стальных конструкций. Микробиологическая активность сульфатредуцирующих бактерий (SRB), присутствующих в верхних осадочных слоях, может усиливать образование продуктов коррозии и, следовательно, значительно влияет на скорость коррозии как артефактов железа и стали в бескислородной морской среде, когда присутствует адекватный органический источник пищи. Сера, высвобождающаяся из материковой породы в результате механических и химических процессов выветривания, в основном переносится в Мировой океан речными поступлениями. Благодаря специфическим реакциям на основе кислорода, преобладающим в поверхностных водах, сера может преобразовываться в сульфат $\left(\mathrm{SO}_{4}^{2-}\right)$, который является доминирующей формой серы в морской воде. В бескислородной морской среде сульфат становится доминирующим избирательным акцептором в анаэробном сульфатном дыхании. В результате этого процесса синтезируется сероводород (Kasten, Jørgensen, 2000). Обогащение среды железом также может способствовать размножению бактерий (Tortell et al., 1999; Jørgensen, 2000).

Примером процессов, характерных для мелководья, где среда более богата кислородом, может служить корабль «Пэппи Лейн» (постройки к. XIX в.), затонувший в Памлико Саунд, штат Северная Каролина. Образцы для анализа были собраны как с самого корабля, так и из окружающих отложений; также были взяты пробы морской воды. Результаты показали, что образцы с затонувшего судна были более похожи друг на друга, чем на те, которые имелись в окружающих осадочных отложениях и водной среде, что позволяет предположить, что они заняли специализированную нишу, связанную с затонувшим кораблем. Были выявлены различия между микробными сообществами в разных частях затонувшего судна, в том числе между заметно корродирующими и не корродирующими частями затонувшего судна. Оценки относительной численности железобактерий (FeOB), которые могут способствовать ухудшению состояния корабля в результате биокоррозии, показали, что они присутствуют на всех участках затонувшего судна, но в наибольшей степени распространены на образцах, содержащих видимые продукты коррозии. Zetaproteobacteria, известный класс морских окислителей железа, также были обнаружены в большем количестве на образцах с видимой коррозией. Из одного из образцов был выделен новый штамм zetaproteobacteria, Mariprofundus ferrooxydans O1 (Price et al., 2020).

Помимо бактерий, на затонувших кораблях также формируются колонии различных беспозвоночных, двустворчатых, мшанок и прочих. Однако они не наносят такого существенного вреда как бактерии (Walker, Schlacher, Schlacher-Hoenlinger, 2007). Гораздо сильнее может оказаться влияние крупных техногенных катастроф, таких как, например, взрыв нефтяной платформы Deepwater Horizon в 2010 г. Исследования показали, что некоторые корабли, расположенные на недостаточной глубине покрылись новыми отложениями, чья структура сильно отличается от общего состава донных отложений (Hamdan et al., 2018; Mugge et al., 2019). 


\section{Заключение}

Обзор приведенной литературы показал, что продуктов коррозии железа в морской воде относительно не много. Вместе с тем, следует отметить, что изъятие образцов для анализа сопряжено с большими трудностями. Некорректный пробоотбор может привести к существенным искажениям данных. В целом, наиболее распространенными являются модификации $\mathrm{FeO}(\mathrm{OH})$, сульфиды и некоторые другие минералы.

В процессе отбора проб и при поднятии их на поверхность выяснилась серьезная подверженность предметов из морской среды воздействию кислорода, который может полностью уничтожить артефакт. Если изъятие производилось корректно, то при соблюдение правил хранения и проведения реставрационных работ артефакты из морского железа могут быть стабилизированы, а деградационные процессы в них замедлены. Также в последнее время разрабатываются новые методы прогнозирования сохранности металлов под водой (Johnson, 2011) и электрохимического мониторинга (Degrigny, Spiteri, 2004).

После извлечения железные предметы могут храниться в воде, в которую сразу после извлечения добавляется ингибитор коррозии. Наиболее часто используемыми ингибиторами коррозии в этом виде пассивной стабилизации являются гидроксид натрия, карбонат натрия и сесквикарбонат натрия. После реставрации в высушенном состоянии предмет передается на постоянное хранение. В условиях музейного хранения наиболее важным фактором сохранности изделий из морского железа является влажность и в целом стабильность показателей, отсутствие кратковременныхперепадовтемпературыивлажности. Рекомендованные условия - $15 \%$ относительной влажности и около $20^{\circ} \mathrm{C}$, освещение не боле 300 люкс. Следует избегать пыли и грязи, а также использовать химически стойкий амортизирующий материал и регулярно осматривать такие артефакты (Bekiü, 2014, p. 94-95).

\section{ЛИТЕРАТУРА}

Bekiü L. 2014. Conservation of underwater archeological finds. Manual. Zadar: International Centre for Underwater Archaeology in Zadar (in English).

Degrigny, C., Spiteri, L. 2004. In Proceedings of Metal 2004 National Museum of Australia Canberra. Canberra: National Museum of Australia Canberra, 315-331 (in English).

Duan, J., Wu, S., Zhang, X., Huang, G., Du, M., Hou, B. 2008. In Electrochimica Acta. 54, 22- 28 (in English).

Fors, Y., Sandström, M. 2006. In Chemical Society reviews. 35, 399-415. (in English).

Gilberg, M. R., Seeley, N. J. 1981. In Studies in Conservation. 26 (2) P. 50-56. (in English).

Hamdan, L., Jennifer, J., Salerno, L., Reed, A., Joye, S., Damour, M. 2018. In Scientific Reports. 8 (1), P. 9057-9064. (in English).

Hamilton, D. L. 1999. In Archives and Museum Informatics. 13 (3), P. 291-323. (in English).

Johnson, D. 2011. In Corrosion. 67 (12), P. 12-50 (in English).

Jørgensen, B. B. 2000. In Horst D. Schulz et Matthias Zabel. (eds.). Marine Geochemistry. Berlin, Heidelberg: Springer, 173-207. (in English).

Kasten, S., Jørgensen, B.B. 2000. In Horst D. Schulz et Matthias Zabel. (eds.). Marine Geochemistry. Berlin, Heidelberg: Springer, 263-281. (in English).

Little, B. J., Gerke, T.L., Lee, J. S. 2014. In Biofouling. 30 (8), 941-948. https://doi.org/10.1080/0892701 4.2014.951039. (in English).

Moore, J. D. 2015. In Journal of Maritime Archaeology. 10 (3), 191-204 (in English).

Mugge, R. L., Brock, M.L., Salerno, J. L., Damour, M., Church, R. A., Lee, J.,S., Hamdan, L.,J. 2019. In Frontiers in Marine Science. 6. Available at: https://www.frontiersin.org/articles/10.3389/fmars.2019.00048/ full (accessed: 25.04.2021) (in English).

North N. A., Pearson C. 1978. In Studies in Conservation. 23 (4), 174-186. (in English).

North, N. A. 1982. In Studies in onservation. 27 (2), 75-83. (in English).

Price, K. A., Garrison, C. E., Richards, N., Field, E. K. 2020. In Frontiers in Microbiology. 11. Available at: https://doi.org/10.3389/fmicb.2020.01897 (accessed: 25.04.2021) (in English).

Rahmanto W. H., Nuryanto R. 2013. Journal of Coastal Development. 5 (2), 67-74. (in English). 
Selwyn L. S., Mckinnon W. R., Argyropoulos V. 2001. Studies in Conservation. Vol. 46 (2), 109-120. (in English).

Selwyn, L. S., Sirois, P. I., Argyropoulos, V. 1999. In Studies in Conservation. 44 (4), 217-232. (in English).

Tortell, P. D., Maldonado, M. T., Granger, J., Price, N. M. 1999. In FEMS Microbiology Ecology. 29 (1), 1-11. (in English).

Walker, S. J., Schlacher, Thomas A., Schlacher-Hoenlinger, M. A. 2007. In Marine Ecology. (28), 435-445 (in English).

\section{Информация об авторе:}

Носова Екатерина Игоревна, кандидат исторических наук, научный сотрудник, СанктПетербургский институт истории РАН (г. Санкт-Петербург, Россия); katerinanossova@gmail.com

\section{About the Author:}

Nosova Ekaterina I. Candidate of Historical Sciences, Saint-Petersburg Institute of History of the Russian Academy of Sciences. Petrozavodskaia Str., 7, Saint-Petersburg, 197110, Russian Federation; katerinanossova@gmail.com 